\title{
Avaliação da forma de inclusão de zeólita e do nível de consumo sobre a digestibilidade da dieta e as características fecais de cães
}

\author{
[Evaluation of zeolite inclusion and level of food intake on diet digestibility and faecal \\ characteristics of dogs] \\ F.G. Lowndes, T.T. Sabchuk, C.M.M. Souza, A.P. Félix*, A. Maiorka, S.G. Oliveira
}

Universidade Federal do Paraná - Curitiba, PR

\begin{abstract}
RESUMO
Objetivou-se avaliar a forma de inclusão da zeólita e de níveis de consumo sobre a digestibilidade da dieta e as características fecais de cães. O experimento 1 avaliou o efeito do nível de consumo (normal e $50 \%$ a mais do que as necessidades) e da inclusão de zeólita $(0$ e $15 \mathrm{~g} / \mathrm{kg})$ sobre a digestibilidade e as características fecais de 12 cães. No experimento 2, foi avaliada a inclusão de 5,15 e $25 \mathrm{~g} / \mathrm{kg}$ de zeólita adicionada na massa ou por cobertura, em seis cães, sobre a digestibilidade da dieta e as características fecais. O experimento 3 avaliou o odor fecal de nove cães consumindo dietas contendo 0 e $15 \mathrm{~g} / \mathrm{kg}$ de zeólita incluída na massa ou por cobertura. A quantidade consumida e a inclusão de zeólita não afetaram a digestibilidade das dietas. O escore e a matéria seca fecal aumentaram com a inclusão de zeólita. A inclusão de zeólita na massa propiciou aumento na digestibilidade das dietas, independentemente do nível de inclusão. A inclusão de $15 \mathrm{~g} / \mathrm{kg}$ de zeólita, adicionada na massa e por cobertura reduziu o odor fecal dos cães. A inclusão de zeólita na massa aumenta a digestibilidade da dieta, a consistência fecal e reduz o odor fecal de cães.
\end{abstract}

Palavras-chave: adsorvente, aluminossilicatos, clinoptilolita

\begin{abstract}
This study aimed to evaluate the form of inclusion of zeolite and consumption levels on diet digestibility and fecal characteristics of dogs. The first experiment examined the effect of consumption level (normal and $50 \%$ higher than the requirements) and zeolite level (0 and 15g/kg) on diet digestibility and fecal characteristics of 12 dogs. In experiment 2 the inclusion of 5,15 and $25 \mathrm{~g} / \mathrm{kg}$ of added zeolite in dough or coating in six dogs on diet digestibility and fecal characteristics was evaluated. The third experiment assessed the fecal odor of nine dogs fed diets containing 0 and $15 \mathrm{~g} / \mathrm{kg}$ of zeolite included in the dough or coating. The amount consumed, as well as the inclusion of zeolite, did not affect diet digestibility. Fecal score and dry matter increased with the inclusion of zeolite. The inclusion of zeolite in the dough provided an increase in diet digestibility, regardless of the level of inclusion. The inclusion of $15 \mathrm{~g} / \mathrm{kg}$ zeolite added to the dough and by coating reduced fecal odor of dogs. The inclusion of zeolite in dough increases diet digestibility, fecal consistency, and reduces the fecal odor of dogs.
\end{abstract}

Keywords: adsorbent, aluminosilicates, clinoptilolita

\section{INTRODUÇÃO}

As zeólitas são aluminossilicatos hidratados de metais alcalinos ou alcalinos terrosos. Seu uso na nutrição animal tem como objetivo adsorver água

Recebido em 22 de setembro de 2016

Aceito em 29 de agosto de 2017

*Autor para correspondência (corresponding author)

E-mail: ananda_felix@yahoo.com.br e gases do trato gastrintestinal (TGI) dos animais de companhia e, dessa maneira, melhorar as características fecais (Maia et al., 2010).

Os resultados encontrados na literatura (Félix et al., 2009; Maia et al., 2010) acerca da inclusão de zeólita na alimentação de cães são 
contraditórios e podem, em parte, ser explicados pela falta de especificação do produto utilizado e pelo tipo de inclusão desse aluminossilicato na dieta. São conhecidas mais de 42 espécies de zeólitas naturais com composição e características distintas (Luz, 1995), corroborando as divergências entre os resultados das pesquisas. Ainda, a ausência de especificação da forma de inclusão do adsorvente às dietas (na massa passando pelo processo de extrusão, ou por cobertura, posterior ao processamento) também é um agravante nesse contexto.

Com a inclusão de zeólita na massa do extrusado, o mineral pode ser saturado pela água adicionada durante o processo. Todavia, essa saturação poderia ser revertida na fase de secagem, em que ocorre a desidratação reversível da rede cristalina da zeólita, deixando o mineral com mais espaços vazios (menor teor de água remanescente). Dessa maneira, a zeólita apresentaria maior potencial para adsorver água e amônia no TGI dos cães. Por outro lado, a inclusão da zeólita por cobertura, junto com o óleo na fase de recobrimento do extrusado, também poderia alterar a sua capacidade adsortiva. A gordura pode propiciar barreira física para a adsorção, já que as zeólitas são polares e, portanto, lipofóbicas (Keer, 1989).

Além do tipo de inclusão da zeólita nas dietas para cães, outro ponto a ser considerado é o fornecimento excessivo de alimento pelos tutores aos seus animais de companhia e também o maior consumo de alimentos por animais com alta demanda energética, como cães atletas ou em crescimento. A ingestão excessiva de alimentos pode aumentar a produção fecal diária, afetando sua consistência e umidade (Case et al., 2000). Os níveis adequados de inclusão de zeólita nessa situação podem ser maiores do que quando em consumo para mantença.

Diante do exposto, o presente trabalho objetiva avaliar o efeito dos métodos de inclusão da zeólita clinoptilolita em dietas extrusadas para cães, quando fornecidas em dois níveis de consumo, sobre a digestibilidade dos nutrientes e as características fecais de cães.

\section{MATERIAL E MÉTODOS}

Foram realizados três experimentos para avaliar os efeitos da zeólita sobre a digestibilidade dos nutrientes da dieta e as características fecais em cães. No experimento 1 , foi avaliada a inclusão de zeólita em dois níveis de consumo alimentar (normal e $50 \%$ a mais do que as necessidades energéticas de cães). No experimento 2, foi avaliado o tipo de inclusão de zeólita na dieta (massa ou por cobertura). No experimento 3, foi avaliado o efeito da inclusão da zeólita por massa ou cobertura na dieta sobre o odor fecal de cães. Os experimentos foram aprovados pela Comissão de Ética no Uso de Animais da Universidade Federal do Paraná, Curitiba, Paraná, Brasil, sob o protocolo ${ }^{\circ}$ 018/2012.

Foram fabricadas sete dietas para cães adultos, constituídas por uma dieta controle $(0 \mathrm{~g} / \mathrm{kg}$ zeólita) e seis dietas contendo adição de $5 \mathrm{~g} / \mathrm{kg}$, $15 \mathrm{~g} / \mathrm{kg}$ e $25 \mathrm{~g} / \mathrm{kg}$ de zeólita (Clinoptilolita, CELPEC, Celta Brasil, Brasil) antes (inclusão na massa) e após a extrusão da dieta (no recobrimento com óleo de frango). A zeólita foi adicionada em substituição ao milho. As dietas foram moídas a $1 \mathrm{~mm}$ em moinho de martelos e extrusadas em extrusora de rosca simples (E130, Ferraz, Ribeirão Preto, Brasil), com taxa de produção média de $1870 \mathrm{~kg} /$ hora. Foram adicionados 330 a $3871 / \mathrm{h}$ de água, com temperatura média de $93^{\circ} \mathrm{C}$, no condicionador. Após extrusão, as dietas foram secas em secador horizontal de tripla esteira, durante 20 minutos, a $105^{\circ} \mathrm{C}$.

A zeólita utilizada foi caracterizada como um produto $100 \%$ natural, composto por aluminossilicato hidratado de estrutura cristalina. Apresentou relação $\mathrm{Si} / \mathrm{Al}$ de 4,25 e CTC de $2,6 \mathrm{mEq} \cdot \mathrm{g}^{-1}$. Os ingredientes e a composição química das dietas estão apresentados na Tab. 1.

Para melhor caracterizar a capacidade adsorvente da zeólita nas dietas experimentais, foi utilizada a metodologia da análise de curva de retenção de água no solo descrita por Gauland (1997). Primeiramente, realizou-se a vedação do fundo dos anéis (cilindros metálicos) com tecido de nylon preso por um atilho de borracha e a pesagem desses anéis. Os anéis foram preenchidos com as rações moídas a $2 \mathrm{~mm}$. A quantidade foi calculada por meio da densidade úmida deles, para garantir a uniformidade de volume. Os anéis foram, então, colocados em bandejas plásticas com água até $1 / 3$ de sua altura, para saturação por 24 horas. Passado esse tempo, os anéis foram retirados da água e pesados. 
Tabela 1. Ingredientes e composição química analisada e calculada (com base na matéria seca) das dietas experimentais

\begin{tabular}{|c|c|c|c|c|c|c|c|}
\hline \multirow{2}{*}{$\begin{array}{l}\text { Ingredientes } \\
(\mathrm{kg} / \text { ton })\end{array}$} & \multicolumn{3}{|c|}{ Zeólita na massa (g/kg) } & \multicolumn{3}{|c|}{ Zeólita em cobertura $(\mathrm{g} / \mathrm{kg})$} & \multirow{2}{*}{ Controle } \\
\hline & 5 & 15 & 25 & 5 & 15 & 25 & \\
\hline Milho & 519,6 & 509,6 & 499,6 & 519,6 & 509,6 & 499,6 & 524,6 \\
\hline Farelo de soja & 150,0 & 150,0 & 150,0 & 150,0 & 150,0 & 150,0 & 150,0 \\
\hline Farinha de carne & 50,0 & 50,0 & 50,0 & 50,0 & 50,0 & 50,0 & 50,0 \\
\hline FVA & 180,0 & 180,0 & 180,0 & 180,0 & 180,0 & 180,0 & 180,0 \\
\hline Ácido cítrico & 0,35 & 0,35 & 0,35 & 0,35 & 0,35 & 0,35 & 0,35 \\
\hline BHA & 0,07 & 0,07 & 0,07 & 0,07 & 0,07 & 0,07 & 0,07 \\
\hline Zeólita $^{\mathrm{a}}$ & 5,0 & 15,0 & 25,0 & 5,0 & 15,0 & 25,0 & 0,0 \\
\hline Colina & 2,0 & 2,0 & 2,0 & 2,0 & 2,0 & 2,0 & 2,0 \\
\hline Premix $^{\mathrm{b}}$ & 3,0 & 3,0 & 3,0 & 3,0 & 3,0 & 3,0 & 3,0 \\
\hline Óleo de frango & 60,0 & 60,0 & 60,0 & 60,0 & 60,0 & 60,0 & 60,0 \\
\hline Palatabilizante & 30,0 & 30,0 & 30,0 & 30,0 & 30,0 & 30,0 & 30,0 \\
\hline Total & 1000,00 & 1000,00 & 1000,00 & 1000,00 & 1000,00 & 1000,00 & 1000,0 \\
\hline \multicolumn{8}{|c|}{ Composição química analisada $(\mathrm{g} / \mathrm{kg})$} \\
\hline Matéria seca & 955,1 & 956,6 & 953,5 & 947,5 & 950,8 & 950,5 & 945,5 \\
\hline Matéria mineral & 90,1 & 95,9 & 101,5 & 101,3 & 104,9 & 115,4 & 93,9 \\
\hline Proteína bruta & 287,9 & 282,6 & 282,3 & 281,53 & 283,5 & 277,9 & 300,1 \\
\hline Fibra bruta & 19,1 & 23,1 & 22,2 & 20,2 & 24,2 & 23,3 & 16,56 \\
\hline Extrato etéreo & 149,0 & 150,6 & 14,97 & 151,9 & 157,3 & 153,7 & 137,68 \\
\hline $\mathrm{Ca}$ & 14,3 & 14,0 & 14,0 & 14,2 & 14,0 & 14,1 & 17,1 \\
\hline $\mathrm{P}$ & 9,7 & 9,6 & 9,4 & 9,3 & 9,5 & 9,3 & 10,2 \\
\hline \multicolumn{8}{|c|}{ Composição química calculada } \\
\hline EM (kcal/kg) & 3721 & 3702 & 3651 & 3611 & 3628 & 3811 & 3604 \\
\hline
\end{tabular}

O volume de água contido na amostra nesse momento corresponde ao ponto zero de tensão, equivalendo à porosidade total (PT). Os anéis foram, então, transferidos para funis de vidro $(25 \mathrm{~cm}$ de diâmetro superior interno), com uma base de placa porosa (pressão de 1 bar e alta condutância) de mesmo diâmetro. Os cilindros foram saturados novamente por 24 horas, com uma lâmina de $0,5 \mathrm{~cm}$ abaixo da borda destes. Em seguida, a tensão foi ajustada para $10 \mathrm{~cm}$ de coluna de água (10hPa), na qual os funis permaneceram por cerca de 48 horas até atingirem o equilíbrio. Posteriormente, os funis foram pesados e os mesmos procedimentos foram repetidos para as tensões 50 e $100 \mathrm{~cm}$ de coluna de água $(50$ e $100 \mathrm{hPa})$. A água facilmente disponível (AFD) foi obtida pelo volume de água liberado entre 10 e $50 \mathrm{~cm}$ de tensão, e a remanescente (AR) pelo volume de água que permaneceu na amostra após esta ser submetida à pressão de sucção de $100 \mathrm{hPa}$, a qual é equivalente à "água de microporos" (Haynes e Goh, 1978). Depois desse processo, as amostras foram secas em estufa a $105^{\circ} \mathrm{C}$. A análise foi realizada em triplicata.

Foram avaliadas as dietas 0 e $15 \mathrm{~g} / \mathrm{kg}$ de zeólita adicionada por cobertura, fornecidas em dois níveis de consumo: normal e $50 \%$ a mais do que as necessidades de energia metabolizável de cães adultos em manutenção (NEM). As NEM dos cães foram calculadas com base na equação: 130 
$x$ peso $(\mathrm{kg})^{0,75}$ (Nutrient..., 2006). Foram utilizados 12 cães (seis machos e seis fêmeas) adultos da raça Beagle, com peso médio de $10 \pm 1,2 \mathrm{~kg}$ e quatro anos de idade. Os animais foram alojados em baias individuais de alvenaria (5 metros de comprimento $\mathrm{x} 2$ metros de largura).

O delineamento utilizado foi o de blocos ao acaso, composto por quatro tratamentos e dois períodos (blocos), em arranjo fatorial $2 \times 2$ (inclusão de zeólita $\mathrm{x}$ nível de consumo), totalizando seis repetições por tratamento. Os cães foram pesados no início e no final do experimento.

Antes do início do experimento, amostras das rações foram analisadas para determinação de matéria seca $(\mathrm{MS})$, proteína bruta $(\mathrm{PB}$, método 954.01), matéria mineral (MM, método 942.05), fibra bruta (FB, método 962.10) e extrato etéreo em hidrólise ácida (EE, método 954.02) segundo a AOAC (Official..., 1995). A energia bruta (EB) foi obtida em bomba calorimétrica (Parr Instrument Co, modelo 1261, Moline, IL, USA).

O ensaio de digestibilidade foi conduzido pelo método de coleta total de fezes, conforme as recomendações da Association of American Feed Control Officials (Dog..., 2003), com cinco dias de adaptação seguidos de cinco dias de coleta total de fezes por período. Os animais foram alimentados uma vez ao dia, às oito horas, segundo o nível de consumo avaliado. A água foi fornecida ad libtum. As fezes foram coletadas, no mínimo, duas vezes por dia, pesadas e congeladas individualmente $\left(-14^{\circ} \mathrm{C}\right)$, constituindo um composto de fezes de cada animal por período de coleta.

$\mathrm{O}$ pH e a amônia foram avaliados em duplicata nas fezes frescas coletadas, no máximo, após 15 minutos de defecação. $\mathrm{O}$ pH fecal foi avaliado em 2,0g de fezes frescas, diluídas em $20 \mathrm{~mL}$ de água destilada usando-se pHmêtro digital (331, Politeste Instrumentos de Teste Ltda., São Paulo, Brasil). O teor de amônia foi determinado segundo Félix et al. (2013). A consistência fecal foi avaliada por meio de escore com graduação de 1 a 5 , sendo 1 o indicativo de fezes pastosas e sem forma, 2 o indicativo de fezes macias e malformadas, 3 o indicativo de fezes macias, formadas e úmidas, 4 o indicativo de fezes bem formadas e consistentes e 5 para fezes bem formadas, duras e secas (Carciofi et al., 2009). Ao final das coletas fecais, a mistura composta das fezes de cada animal foi descongelada, homogeneizada e submetida à secagem em estufa a $55^{\circ} \mathrm{C}$ (320-SE, Fanem, São Paulo, Brasil) por 72 horas e posterior moagem a $1 \mathrm{~mm}$ em moinho (Wiley hammer Mill, Arthur H. Thomas Co., Philadelphia, PA), para determinação dos teores de UM, PB, MM, FB, EEA e EB.

Com base nos resultados laboratoriais obtidos, os CDA e a EM das variáveis analisadas foram calculados por meio das equações propostas pela AAFCO (Dog..., 2003):

$\mathrm{CDA}=(\mathrm{g}$ nutriente ingerido $-\mathrm{g}$ nutriente excretado) / g nutriente ingerido;

$\mathrm{EM}(\mathrm{kcal} / \mathrm{kg})=\{\mathrm{kcal} / \mathrm{g}$ energia bruta ingerida $\mathrm{kcal} / \mathrm{g}$ energia bruta excretada nas fezes - [(g proteína bruta ingerida - g proteína bruta excretada nas fezes) x $1,25 \mathrm{kcal} / \mathrm{g}] \mathrm{g} / \mathrm{g}$ alimento ingerido.

No experimento 2, foram avaliadas as dietas com inclusão de 0,15 e $25 \mathrm{~g} / \mathrm{kg}$ de zeólita na massa e por cobertura. Foram utilizados seis cães (três machos e três fêmeas) adultos da raça Beagle, com peso médio de $10+1,2 \mathrm{~kg}$ e quatro anos de idade. $\mathrm{O}$ delineamento experimental utilizado foi o quadrado latino $6 \times 6$, em arranjo fatorial $2 \times 3$ (forma de adição x nível de inclusão), totalizando seis repetições por tratamento.

Os cães foram alimentados duas vezes ao dia (oito horas e 16h), em quantidade suficiente para suprir suas NEM, segundo o NRC (Nutrient..., 2006). Os animais foram alojados nas mesmas condições descritas anteriormente, sendo seguido o mesmo protocolo de coletas e análises.

Para o experimento 3 (análise sensorial das fezes), foram utilizados nove cães (cinco machos e quatro fêmeas) adultos da raça Beagle, com peso médio de $10 \pm 1,2 \mathrm{~kg}$ e quatro anos de idade, com as mesmas condições experimentais descritas no primeiro experimento. $\mathrm{O}$ delineamento experimental utilizado foi $\mathrm{o}$ inteiramente ao acaso. Foram avaliados três tratamentos: $0 \mathrm{~g} / \mathrm{kg}$ e $15 \mathrm{~g} / \mathrm{kg}$ de inclusão de zeólita na massa e por recobrimento. Os cães foram alimentados durante seis dias, conforme descrito no experimento 2. Ao sexto dia experimental, foram coletadas as fezes dos animais e separados $10 \mathrm{~g}$ de cada animal, 
totalizando mistura de $30 \mathrm{~g}$ de fezes para cada tratamento, destinadas à análise sensorial de odor, adaptando-se a metodologia descrita por Morales (1994). Os potes foram identificados como: A (dieta controle), B (15g/kg zeólita na massa) e C (15g/kg zeólita por cobertura). A análise sensorial foi feita às $12 \mathrm{~h} 30 \mathrm{~min}$ por 50 avaliadores, que desconheciam os tratamentos experimentais. A avaliação foi realizada comparando-se as amostras $\mathrm{B}$ e $\mathrm{C}$ em relação à padrão (A), e foram atribuídos valores em relação ao odor: 1- melhor que a padrão (menos fétido/intenso); 2- igual à padrão e 3- pior que a padrão (mais fétido/intenso).

Os resultados dos três experimentos foram submetidos à análise quanto à normalidade, pelo teste Shapiro-Wilk, e à heterocedascidade das variâncias, pelo teste de Bartlett. Os resultados homocesdásticos de digestibilidade e consumo foram analisados utilizando-se o procedimento GLM do pacote estatístico SAS (Statistical..., NC, USA). Quando houve interação significativa, as médias foram comparadas pelo teste de Tukey a 5\% de probabilidade. Os resultados da curva de retenção de água, digestibilidade e características fecais foram avaliados por correlação de Pearson, utilizandose o procedimento CORR, também do pacote estatístico SAS. Os resultados da análise sensorial, que foram não paramétricos, foram avaliados pelo teste de Kruskall-Wallis a 5\% de significância.

\section{RESULTADOS}

As maiores porcentagens de PT e AFD foram obtidas ao se incluir a zeólita na massa, enquanto maiores teores de AR foram observados ao se incluir o mineral por cobertura (Tab. 2).

Tabela 2. Porosidade total (PT), água facilmente disponível (AFD) e água remanescente (AR) de dietas contendo zeólita adicionada na massa ou por cobertura

\begin{tabular}{ccccc}
\hline \multicolumn{6}{c}{ Dietas (g/kg zeólita) } & PT (\%) & AFD (\%) & AR (\%) \\
\multirow{3}{*}{ Massa } & 5 & 89,26 & 10,68 & 42,41 \\
& 15 & 87,45 & 12,34 & 37,05 \\
\multirow{4}{*}{ Cobertura } & 25 & 79,65 & 5,28 & 50,33 \\
& 5 & 79,68 & 3,88 & 55,54 \\
& 15 & 81,14 & 7,16 & 51,70 \\
& 25 & 79,84 & 6,41 & 53,84 \\
\hline
\end{tabular}

No experimento 1 , tanto o nível de consumo de alimento como o nível de inclusão de zeólita não afetaram a digestibilidade dos nutrientes e a EM das dietas $(\mathrm{P}>0,05)$. Mesmo com o maior consumo de alimento ( $50 \%$ a mais das NEM), a inclusão de zeólita aumentou o escore e a matéria seca fecal dos cães $(\mathrm{P}<0,05)$. Como esperado, o consumo e a variação de peso dos animais foram superiores quando eles foram alimentados com $50 \%$ a mais que suas NEM $(\mathrm{P}<0,05$, Tab. 3$)$.

No experimento 2, a inclusão de zeólita na massa propiciou maiores valores de digestibilidade dos nutrientes em relação à zeólita adicionada em cobertura $(\mathrm{P}<0,05)$. Não houve efeito do nível de inclusão de zeólita sobre os CDA e EM das dietas $(\mathrm{P}>0,05)$. Houve interação entre o nível e o tipo de inclusão de zeólita apenas para o CDA da MO $(\mathrm{P}<0,05)$. As características fecais não diferiram $(\mathrm{P}>0,05)$ entre os tratamentos (Tab. 4).

A PT e a AFD correlacionaram-se positivamente com os CDA da EB, MS, PB $(\mathrm{P}<0,05)$ e $\mathrm{MO}$ $(\mathrm{P}<0,01)$. A AR correlacionou-se negativamente com os CDA da MS $(\mathrm{P}<0,05), \mathrm{EB}, \mathrm{MO}$ e $\mathrm{PB}$ $(\mathrm{P}<0,01)$. A PT, a AFD e a AR não apresentaram correlação com as características fecais, CDA do EE e com a EM da dieta ( $\mathrm{P}>0,05$, Tab. 5).

No experimento 3, a inclusão de $15 \mathrm{~g} / \mathrm{kg}$ de zeólita na massa e por cobertura foi suficiente para reduzir o odor fecal de cães em comparação às fezes dos animais alimentados com a dieta controle $(\mathrm{P}<0,05$, Tab. 6). 
Tabela 3. Coeficientes de digestibilidade aparente (CDA) dos nutrientes, energia metabolizável (EM, $\mathrm{kcal} / \mathrm{kg}$ ), consumo das dietas ( $\mathrm{g} / \mathrm{kg}$ de peso corporal) e características fecais de cães alimentados com dietas contendo ou não zeólita, fornecidas em quantidade normal e $50 \%$ a mais que as necessidades dos animais

\begin{tabular}{|c|c|c|c|c|c|c|c|c|}
\hline & \multicolumn{2}{|c|}{$\begin{array}{c}\text { Fornecimento } \\
\text { normal }\end{array}$} & \multicolumn{2}{|c|}{ Fornecimento $50 \%$} & \multirow[t]{2}{*}{ EPM } & \multicolumn{3}{|c|}{$\mathrm{P}$} \\
\hline & $0 \mathrm{~g} / \mathrm{kg}$ & $15 \mathrm{~g} / \mathrm{kg}$ & $0 \mathrm{~g} / \mathrm{kg}$ & $15 \mathrm{~g} / \mathrm{kg}$ & & $\mathrm{F}$ & I & $\mathrm{IxF}$ \\
\hline Consumo & 21,422 & 21,384 & 25,810 & 25,731 & 0,481 & $<0,001$ & 0,863 & 0,718 \\
\hline VP & $-0,233$ & $-0,254$ & 0,322 & 0,345 & 0,085 & $<0,001$ & 0,808 & 0,572 \\
\hline PF & 176,33 & 158,25 & 205,83 & 198,63 & 7,404 & 0,214 & 0,014 & 0,323 \\
\hline \multicolumn{9}{|c|}{$\mathrm{CDA}$} \\
\hline EB & 0,825 & 0,847 & 0,819 & 0,828 & 0,086 & 0,503 & 0,388 & 0,717 \\
\hline $\mathrm{EE}$ & 0,873 & 0,907 & 0,887 & 0,874 & 0,066 & 0,648 & 0,594 & 0,155 \\
\hline $\mathrm{MO}$ & 0,819 & 0,821 & 0,812 & 0,826 & 0,054 & 0,475 & 0,924 & 0,591 \\
\hline MS & 0,754 & 0,743 & 0,745 & 0,751 & 0,077 & 0,972 & 0,887 & 0,627 \\
\hline PB & 0,821 & 0,827 & 0,812 & 0,806 & 0,070 & 0,477 & 0,981 & 0,800 \\
\hline EM & 3783 & 3852 & 3757 & 3766 & 0,016 & 0,502 & 0,630 & 0,718 \\
\hline Amônia (\%) & 0,081 & 0,102 & 0,094 & 0,103 & 0,012 & 0,300 & 0,061 & 0,107 \\
\hline $\mathrm{pH}$ & 6,513 & 7,115 & 6,685 & 6,720 & 0,087 & 0,492 & 0,060 & 0,091 \\
\hline Escore & 3,1 & 3,6 & 3,0 & 3,5 & 0,091 & 0,516 & 0,004 & 0,766 \\
\hline $\operatorname{MSf}(\%)$ & 34,35 & 37,05 & 32,77 & 37,03 & 0,624 & 0,457 & 0,003 & 0,471 \\
\hline
\end{tabular}

VP: variação de peso dos animais (peso final - inicial, g); PF: produção fecal diária (g/animal/dia na matéria natural; EB: energia bruta; EE: extrato etéreo em hidrólise ácida; MO: matéria orgânica; MS: matéria seca; PB: proteína bruta; MSf: matéria seca fecal; EPM: erro-padrão da média; I: nível de inclusão de zeólita; F: fornecimento; IxF: interação entre os fatores nível $\mathrm{x}$ fornecimento.

Tabela 4. Coeficientes de digestibilidade aparente (CDA) dos nutrientes, energia metabolizável (EM, $\mathrm{kcal} / \mathrm{kg}$ ), consumo ( $\mathrm{g} / \mathrm{kg}$ de peso corporal) e características fecais de cães alimentados com dietas contendo níveis crescentes de zeólita na massa do extrusado ou por cobertura

\begin{tabular}{|c|c|c|c|c|c|c|c|c|c|c|}
\hline & \multicolumn{3}{|c|}{ Inclusão massa (g/kg) } & \multicolumn{3}{|c|}{ Inclusão cobertura (g/kg) } & \multirow[t]{2}{*}{ EPM } & \multicolumn{3}{|c|}{$\mathrm{P}$} \\
\hline & 5 & 15 & 25 & 5 & 15 & 25 & & $\mathrm{I}$ & $\mathrm{N}$ & IxT \\
\hline Consumo & 17,166 & 17,166 & 17,166 & 17,166 & 17,166 & 17,166 & 0,267 & 1,000 & 1,000 & 1,000 \\
\hline \multicolumn{11}{|c|}{ CDA } \\
\hline EB & 0,831 & 0,842 & 0,819 & 0,769 & 0,813 & 0,793 & 0,059 & $<0,001$ & 0,056 & 0,250 \\
\hline $\mathrm{EE}$ & 0,888 & 0,892 & 0,889 & 0,851 & 0,888 & 0,878 & 0,048 & 0,069 & 0,205 & 0,334 \\
\hline MO & $0,823^{\mathrm{ab}}$ & $0,841^{\mathrm{a}}$ & $0,806^{\mathrm{ab}}$ & $0,758^{\mathrm{c}}$ & $0,759^{\mathrm{c}}$ & $0,781^{\mathrm{bc}}$ & 0,065 & $<0,001$ & 0,680 & 0,029 \\
\hline MS & 0,788 & 0,796 & 0,768 & 0,730 & 0,776 & 0,737 & 0,070 & 0,005 & 0,074 & 0,424 \\
\hline PB & 0,797 & 0,800 & 0,770 & 0,717 & 0,763 & 0,743 & 0,070 & 0,001 & 0,125 & 0,132 \\
\hline EM & 3862 & 3976 & 3895 & 3668 & 3668 & 3706 & 0,030 & 0,144 & 0,954 & 0,936 \\
\hline Amônia & 0,093 & 0,101 & 0,102 & 0,087 & 0,086 & 0,092 & 0,001 & 0,055 & 0,577 & 0,782 \\
\hline $\mathrm{pH}$ & 7,015 & 7,080 & 6,991 & 6,836 & 6,945 & 6,853 & 0,058 & 0,226 & 0,793 & 0,987 \\
\hline Escore & 3,4 & 3,6 & 3,5 & 3,3 & 3,5 & 3,4 & 0,044 & 0,268 & 0,360 & 0,854 \\
\hline MSf & 31,3 & 33,5 & 33,5 & 34,2 & 35,0 & 36,0 & 0,678 & 0,104 & 0,475 & 0,902 \\
\hline
\end{tabular}

EB: energia bruta; EE: extrato etéreo em hidrólise ácida; MO: matéria orgânica; MS: matéria seca; PB: proteína bruta; EM: energia metabolizável; amônia (\%); MSf: matéria seca fecal (\%); EPM: erro-padrão da média; P: probabilidade; I: tipo de inclusão; N: nível de inclusão; IxN: interação entre os fatores tipo e nível de inclusão. Médias seguidas por letras distintas diferem pelo teste de Tukey $(\mathrm{P}<0,05)$. 
Tabela 5. Correlação entre porosidade total (PT), água facilmente disponível (AFD), água remanescente (AR), características fecais, coeficientes de digestibilidade dos nutrientes e energia metabolizável (EM) de dietas contendo 5,15 e $25 \mathrm{~g} / \mathrm{kg}$ de zeólita na massa e por cobertura

\begin{tabular}{cccc}
\hline & PT & AFD & AR \\
\hline MSf & $-0,2960$ & $-0,2044$ & 0,2116 \\
Amônia & 0,0796 & 0,1958 & $-0,2694$ \\
pH & 0,1619 & 0,2410 & $-0,2590$ \\
\hline & Coeficiente de digestibilidade aparente & \\
\hline EB & $0,4371^{*}$ & $0,4970^{*}$ & $-0,5914^{* *}$ \\
EE & 0,2072 & 0,2931 & $-0,3017$ \\
MO & $0,5911^{* *}$ & $0,5888^{* *}$ & $-0,7273^{* *}$ \\
MS & $0,4107^{*}$ & $0,4231^{*}$ & $-0,4254^{*}$ \\
PB & $0,5121^{*}$ & $0,5223^{*}$ & $-0,5985^{* *}$ \\
EM & 0.1242 & 0.1260 & -0.2362 \\
\hline MSf matéria
\end{tabular}

MSf, matéria seca fecal; CDA, coeficiente de digestibilidade aparente; EB, energia bruta; EE, extrato etéreo em hidrólise ácida; $\mathrm{MO}$, matéria orgânica; $\mathrm{MS}$, matéria seca; $\mathrm{PB}$, proteína bruta $\left({ }^{*} \mathrm{P}<0,05 ;{ }^{*} \mathrm{P}<0,001\right)$.

Tabela 6. Medianas do odor fecal de cães alimentados com dieta contendo $15 \mathrm{~g} / \mathrm{kg}$ de zeólita na massa antes da extrusão e $15 \mathrm{~g} / \mathrm{kg}$ de zeólita adicionada posteriormente ao processo de extrusão, em relação a uma dieta controle com $0 \mathrm{~g} / \mathrm{kg}$ de zeólita

\begin{tabular}{ccccc}
\hline & $0 \%$ zeólita & $\begin{array}{c}15 \mathrm{~g} / \mathrm{kg} \text { zeólita } \\
\text { Massa }\end{array}$ & $\begin{array}{c}15 \mathrm{~g} / \mathrm{kg} \text { zeólita } \\
\text { Cobertura }\end{array}$ & $\mathrm{P}$ \\
\hline Odor fecal & $2,0^{\mathrm{a}}$ & $1,0^{\mathrm{b}}$ & $1,0^{\mathrm{b}}$ & $<0,001$ \\
\hline
\end{tabular}

${ }^{\mathrm{a}, \mathrm{b}}$ Medianas seguidas por letras distintas diferem pelo teste de Kruskal-Wallis $(\mathrm{P}<0,05)$.

$1,0=$ odor melhor que $0 \%$ zeólita; $2=$ odor igual a $0 \%$ zeólita; $3=$ odor pior que $0 \%$ zeólita.

\section{DISCUSSÃO}

Os cães, pelos hábitos caçadores e de competição na alimentação de seus ancestrais, são animais que apresentam o TGI adaptado à ingestão de grandes quantidades de alimento (Case et al., 2000). Desse modo, o consumo de quantidade de alimento $50 \%$ superior às suas necessidades não afetou a digestibilidade dos nutrientes da dieta $\mathrm{e}$ a consistência fecal dos cães, embora tenha aumentado a produção de fezes.

Apesar do aumento na excreção de fezes decorrente do maior consumo, a adição de $15 \mathrm{~g} / \mathrm{kg}$ de zeólita na dieta foi suficiente para aumentar a consistência fecal (escore e matéria seca) dos cães. Essa melhora na consistência fecal corrobora os resultados encontrados por Félix et al. (2009) e Maia et al. (2010), em estudos sobre zeólita em cães, e se deve à sua alta capacidade adsorvente de umidade. Em vista disso, é interessante que, em situações de maior consumo e produção fecal, como em cães atletas e de grande porte, por exemplo, a zeólita seja adicionada à dieta. Cães com alta atividade física, como cães de pastoreio e corrida, por exemplo, podem apresentar NEM duas a três vezes superiores às necessidades de mantença
(Nutrient..., 2006). Assim, é relevante que novos estudos sejam conduzidos para avaliarem níveis de inclusão ótimos de zeólita em dietas para cães que apresentem consumo alimentar superior a $50 \%$ das necessidades de mantença.

$\mathrm{O}$ aumento na digestibilidade dos nutrientes com a adição da zeólita na massa pode estar relacionado à maior capacidade adsorvente do mineral, promovida pelo processo de extrusão e secagem. Durante o processamento, especificamente na etapa de secagem, a temperatura de 110 a $120^{\circ} \mathrm{C}$ pode promover a desidratação endotérmica reversível da rede cristalina da zeólita (Dana, 1981). A remoção de umidade pelo aquecimento aumenta o volume de vazios da zeólita (Harben e Kuzvart, 1996) e a deixa mais acessível para adsorver água e gases do TGI dos animais. A interação entre o nível e o tipo de inclusão de zeólita sobre o CDA da MO demonstrou, no presente estudo, que são necessários maiores níveis de inclusão de zeólita em cobertura para se atingirem os mesmos valores de digestibilidade das dietas contendo zeólita na massa.

Estudos afirmam que a propriedade adsorvente dos minerais da família das zeólitas reduz a taxa 
de passagem do alimento no TGI, promovendo maior tempo de ação das enzimas digestivas e aumento na digestibilidade dos nutrientes (Luz, 1995; Olver, 1997; Parisini et al., 1999). Os aluminossilicatos são minerais lipofóbicos (Keer, 1989), portanto têm pouca atratividade por compostos gordurosos e apolares. Esse comportamento possivelmente prejudicou a ação da zeólita quando aplicada por cobertura junto ao banho de óleo, resultando em menores teores de digestibilidade dos nutrientes em relação às dietas com inclusão de zeólita na massa.

Os maiores teores de PT e AFD nas dietas com inclusão de zeólita na massa do extrusado podem estar relacionados com a sua adequada mistura e a desidratação endotérmica da rede cristalina da zeólita durante a secagem. Quando a zeólita é adicionada posteriormente ao banho de óleo, na cobertura, pode não haver adequada adesão ao extrusado, por ser um material lipofóbico (Keer, 1989). Ainda, os lipídios podem promover barreira física, dificultando a adsorção de água do TGI pela zeólita.

Não foram encontrados na literatura outros trabalhos que avaliassem a PT, a AFD e a AR de dietas extrusadas contendo zeólita.

Segundo Neves e Schvartzman (2005), a porosidade é o parâmetro mais importante correlacionado à estrutura dos aluminossilicatos, uma vez que afeta suas propriedades físicas, como capacidade de adsorção e troca iônica. Os teores de AR foram inversamente proporcionais à digestibilidade dos nutrientes. Portanto, quanto mais AR estiver no mineral, menos espaços vazios este tem disponível para adsorver substâncias no TGI dos animais, o que justifica os teores mais elevados de PT e AFD terem promovido maior digestibilidade dos nutrientes no presente estudo.

Apesar de a forma de inclusão de zeólita ter afetado a sua porosidade e a digestibilidade da dieta, ela não influenciou significativamente as características fecais dos cães. Desse modo, a inclusão de $5 \mathrm{~g} / \mathrm{kg}$ de zeólita já é suficiente para aumentar a MS e o escore e reduzir o odor fecal dos cães. Segundo Houssain et al. (1999), o odor fecal é proveniente da formação de compostos durante a fermentação microbiana intestinal, em que se destacam amônia, aminas alifáticas, ácidos graxos de cadeia ramificada, indóis, fenóis e compostos saturados voláteis. Dentre todos esses compostos, o mais comumente mensurado em ensaios de digestibilidade é a amônia fecal. Tal análise pode não ser suficiente para mensurar o odor fecal, já que outros gases estão envolvidos nesse processo. Portanto, deve, sempre que possível, ser acompanhada de uma análise sensorial de odor.

O odor fecal de cães alimentados com dietas contendo zeólita foi avaliado por Maia et al. (2010). Os autores também obtiveram redução no odor fecal de cães quando suplementados com $7,5 \mathrm{~g} / \mathrm{kg}$ e $10 \mathrm{~g} / \mathrm{kg}$ de zeólita, em relação à dieta controle. A redução do odor fecal promovida pela zeólita ocorre pela sua elevada superfície interna $\left(1000 \mathrm{~m}^{2} / \mathrm{g}\right)$ e capacidade de troca cationica $(200 \mathrm{meq} / 100 \mathrm{~g})$. Isso garante maior facilidade desse mineral em adsorver outras substâncias, como os gases da fermentação intestinal (Castaign, 1994). Além disso, o fato de a zeólita ter reduzido a umidade das fezes também contribui para a menor volatilização de compostos odoríferos (Félix et al., 2009).

\section{CONCLUSÕES}

Os processos de extrusão e secagem podem aumentar a porosidade total da zeólita em relação à sua adição por cobertura. Ainda, a porosidade total apresenta correlação positiva com a digestibilidade da dieta. Desse modo, recomenda-se a inclusão de $15 \mathrm{~g} / \mathrm{kg}$ de zeólita na massa para aumentar a digestibilidade da dieta e a consistência fecal e reduzir o odor das fezes dos cães. Inclusive, com $50 \%$ a mais de consumo de alimento, a inclusão de $15 \mathrm{~g} / \mathrm{kg}$ de zeólita na dieta aumenta a consistência fecal dos cães.

\section{REFERÊNCIAS}

CARCIOFI, A.C.; OLIVEIRA, L.; VALÉRIO, A. et al. Comparison of micronized whole soya to common protein sources in dry dog and cat diets. Anim. Feed Sci. Technol., v.151, p.251260, 2009.

CASE, L.P.; CAREY, D.P.; HIRAKAWA, D.A. Canine and feline nutrition: a resource for companion animal professionals. 2.ed. St. Louis: Mosby, 2000. 592p. 
CASTAING, J. Effect de i'inclusion de spiolite "EXAL" selon les terneurs em cellulose brute et matière grasse d'aliment pour porcs charcutiers. J. Rec. Porcine Fr., v.26, p.199-205, 1994.

DANA, J.D. Manual de mineralogia (DanaHurlbut). São Paulo: S.A., 1981, 642p.

DOG and cat nutrient profiles. Oxford: AAFCO, 2003.

FÉLIX, A.P.; ZANATTA, C.P.; BRITO C.B. et al. Suplementação de manoligossacarídeos (MOS) e uma mistura de alumino silicatos na qualidade das fezes de cães adultos. Arch. Vet. Sci., v.14, p.31-35, 2009.

FELIX, A.P.; ZANATTA, C.P.; BRITO, C.B.M. et al. Digestibility and metabolizable energy of raw soybeans manufactured with different processing treatments and fed to adult dogs and puppies. J. Anim. Sci., v.91, p.2794-2801, 2013.

GAULAND, D.C.S.P. Relações hídricas em substratos à base de trufas sob o uso dos condicionadores casca de arroz carbonizada ou queimada. 1997. 118f. Dissertação (Mestrado em Agronomia) - Universidade Federal do Rio Grande do Sul, Porto Alegre, RS.

HARBEN, P.W.; KUZVART, M. Industrial minerals - a global geology. London: Industrial Minerals Information, 1996. 462p.

HAYNES, R.J.; GOH, K.M. Evaluation of potting media for commercial nursery production of container-grow plants: IV - physical properties of a range amendment peat-based media. $J$. Agric. Res., v.21, p.449-456, 1978.
HOUSSAIN, S.; BERTECHINI, A.G.; NOBRE, P.T.C. Efeito da Zeólita natural e níveis de cálcio no desempenho e características do plasma de tíbia de frango de corte. Arq. Bras. Med. Vet. Zootec., v.46, p.545-552, 1994.

KEER, G.T. Synthetic zeolites. Sci. Am., p.8287, 1989.

LUZ, A.B. Zeólitas: propriedades e usos industriais. Rio de Janeiro: CETEM CNPq, 1995. 68p. (Série Tecnologia Mineral, 68).

MAIA, G.V.C.; SAAD, F.M.O.B.; ROQUE, N.C. et al. Zeólitas e yucca schidigera em rações para cães: palatabilidade, digestibilidade e redução de odores fecais. Rev. Bras. Zootec., v.39, p.2442-2446, 2010.

MORALES, A.A. La evaluación sensorial de los alimentos en la teoria y la prática. Zaragoza: Acriba, 1994. 198p.

NEVES, C.F.; SCHVARTZMAN, M.A. Separação de $\mathrm{CO} 2$ por meio de tecnologia PSA. Quim. Nova, v.28, p.622-628, 2005.

NUTRIENT requirements of dogs and cats. Washington: National Academy, 2006. 428p.

OFFICIAL methods of analysis. 16.ed. Washington: AOAC, 1995. 115p.

OLVER, M.D. Effect of feeding zeolite on the performance of 3 strains of laying hens. $\mathrm{Br}$. Poult. Sci., v.38, p.220-222, 1997.

PARISINI, P.; MARTELLI, G.; SARDI, L.; ESCARBINO, F. Protein and energy retention in pigs fed diets containing sepiolite. Anim. Feed Sci. Technol., v.79, p.155-162, 1999.

STATISTICAL analysis system. Version 8. Cary: SAS Institute, 2009. 